\title{
Supply Chain Performance Measures for gaining Competitive Advantage: A Review
}

\author{
Ambuj Khare (Corresponding author) \\ Birla Institute of Technology \\ India \\ Tel: +968-950-76845Ｅ-mail: ambujkhare@gmail.com
}

\author{
Anurag Saxsena \\ School of Management Studies \\ Indira Gandhi National Open University \\ New Delhi- 110068, India \\ E-mail: anurags@ignou.ac.in
}

Peeyush Teewari

Birla Institute of Technology, International Center

Ras Al Khaimah ,United Arab Emirates

E-mail: peeyushtewari@gmail.com

Received: March 24, 2012

Accepted: April 3, $2012 \quad$ Published: April 15, 2012

doi: 10.5430/jms.v3n2p25

URL: http://dx.doi.org/10.5430/jms.v3n2p25

\begin{abstract}
A supply chain embodies all such activities that influence timing, cost, quality and delivery of a product. Increased competitiveness has forced the supply chains to create new standards for improving processes. Since a benchmark is a standard that is aspired by observing a best practice, it is of immense importance in SCM. Also, supply chains are rooted with the "extended" concept meaning that it includes suppliers, distributors and various processes involving them. Thus a single performance measure does not suffice for the entire chain. Therefore, Benchmarking and Supply chain performance measures are of prime importance in supply chain management context. This paper is an attempt to review some approaches to measure the supply performance.
\end{abstract}

Keywords: Supply Chain, Benchmarking, Best Practices, Competitive Advantage

\section{Introduction}

Sometimes companies wonder if they are putting in as much efforts as its competitor, although is the market leader but still the competitor is offering good products or maintaining a low price and earning more profit. In this case it is mandatory to assess the performance of the operations in supply chain and seek improvements. It is here that best practices and benchmarking comes into picture. Benchmarking helps in identifying the factors that are critical for success. It also portrays the factors that are less important but consuming more resources. Since the business environment is changing rapidly, there is a need for setting new benchmarks.

As it is said that companies do not compete, but their supply chains compete. It is imperative for a company to measure the performance of its supply chain and bring improvements across the extended supply chain in meeting the end-customer requirements. To win in present competitive environment supply chains require continuous improvements and hence are prime indicators for a performance measurement. In SCM context, performance measurement can facilitate inter-understanding and integration among the supply chain members. "There is tremendous value to retailers who participate in the next segment of the retail best practices review. It will enable them to look beyond the bounds of their distribution networks and begin to identify opportunities that will strengthen their supply chains," said Jim Tompkins (2005), President of Tompkins Associates, the leading supply chain consulting and integration firm. 


\section{Best Practices and Benchmarking}

What is meant by a benchmark? In simplest terms, a benchmark is a standard that is aspired by observing a best practice. One can witness this phenomenon in sports- sportspersons are consciously aware of the Olympic records and World records and they continually seek to achieve that level first and then improve upon it. There are no surprises in this as everybody aspires to become the best and that level, which will make him best, is called as a "benchmark" for him. In context of supply chain management, products, services and practices replace sportspersons. The companies that are the toughest competitors or the market leaders replace the record holders. In both case the ultimate aim is continuous improvement. Let us revisit the sportsperson, he first identifies his own performance and then aspires to achieve the level of the best competitor. A company in the similar manner reviews its existing processes, sets a standard to judge or measure and finally tries to achieve that standard. The common goal again is to gain competitive advantage. Thus, Benchmarking is a method of comparison of performance in order to create new standards for improving processes. Waters (2003) puts it in the following manner, "To be blunt, organizations use benchmarking to find ideas for logistics that they can copy or adapt".

Benchmarking helps in identifying the factors that are critical for success. It also portrays the factors that are less important and thus needing lesser pie from the resources. These things are fundamental for the long-term success of any business. Since the business environment is changing rapidly, there is a need for setting new benchmarks. Supply chain embodies all such activities that influence timing, cost, quality and delivery of a product. Increased competitiveness has forced the businesses to look into matters of quality and costs.

The need for benchmarking arises when the company wishes to improve its operations or supply chain; wants to bring organizational changes; enter into some mergers and acquisitions; receives some competitive pressures or initiates some cost reduction actions.

According to Mike Donovan (2005), president of R. Michael Donovan \& Co. Inc., an international management-consulting firm, a company should ask many questions about its supply chain characteristics as an initial benchmark. Some of these questions are pertaining to the realization of the strengths and weaknesses of the supply chain sub-processes, generation of information flow by the supply chain system, orientation and training of personnel on supply chain processes, whether supply chain works on pull or push technology, whether continuous improvements are dome with supply chain processes, continual improvement of logistical business models and usage of e-commerce and technology etc. Benchmarking is not a trivial process and needs a lot of efforts from organizations because the efforts here are directed towards comparing oneself with the "best in the trade" and about reaching that level.

Benchmarking is related to Kaizen philosophy that says that everything has to continuously improve. Kaizen is a Japanese management concept whose key elements are quality, effort, involvement of all employees, willingness to change and communication. Actually, $\mathrm{K}$ in Kaizen means Kai (Change) and Zen means (Good). So, Kaizen is all about making changes to become good. Benchmarking is also the same as it also intends to make changes for achieving the best.

\section{Measuring Supply Chain Performance}

The definition of Supply Chain Management as per Council of Logistics Management is, "Supply Chain Management (SCM) is the systemic, strategic coordination of the traditional business functions and the tactics across these business functions within a particular company and across businesses within the supply chain for the purposes of improving the long-term performance of the individual companies and the supply chain as a whole". Now if we talk about measuring the performance of supply chain, we are probably talking about a large number of performance measures for different systems such as production/ operation, distribution and inventory etc. Chan et al. (2003) commented, "As an indispensable tool, performance measurement provides the necessary assistance for performance improvement in pursuit of supply chain excellence".

The main difference between supply chain performance measure and other performance measures lies in the "extended" concept of a supply chain where it includes suppliers and distributors etc. Thus single performance measure does not suffice for the entire chain. There are many supply chain metrics such as lead-time, inventory levels, return-on-assets and overall profits etc. but they do not point out many aspects that are important for the supply chain. Thus the need is for measures that capture performance across the entire supply chain. Thus there is a need of measures that are not just single enterprise single measure but are also multiple enterprises multiple measures type. Beamon (1996) defined some characteristics that can be used in evaluation of measurement systems as, "inclusiveness (measurement of all pertinent aspects), universality (allow for comparison under various operating conditions), measurability (data required are measurable) and consistency (measures consistent with organization goals)". 


\section{Supply Chain Performance Measure Systems}

There are a number of performance measures that are available. All these different performance measure systems have different views for integrating supply chain performance measures. These performance measure system answer basic question like what is to be measured, what measures are to be integrated and what is the frequency of integration etc. According to Morgan (2004), "performance measurement is related to strategic intent, and the broad set of metrics used by managers to monitor and guide an organization within acceptable and desirable parameters". Similarly John T. Mentzer (2007) mentioned "In benchmarking the Supply Chain Management (SCM) practices of hundreds of companies, we have learned that many companies actually achieve competitive advantage by leveraging the management of their supply chains" for this "Stick to your core competencies and outsource non-core competencies". Some important supply chain performance measurement systems are as follows:

\subsection{Framework of Kaplan and Norton (1992)}

This framework is also called Supply chain balanced scorecard. Kaplan and Norton (1992) proposed this approach. It analyses weaknesses of the old approaches and prescribes the strategy to exercise a "balance". It views the organization from four perspectives viz. learning and growth perspective; business process perspective; customer perspective and the financial perspective. Balanced scorecard approach embeds concepts like total quality management (TQM); customer defined quality; continuous improvement; empowerment and feedback \& evaluation to view the success of entire supply chain. Let us discuss the four perspectives of balanced scorecard approach.

- Learning and growth perspective: This perspective comprises of employee training and attitude development for self-improvement. It stresses that in the present knowledge dominant world; there is a need for employees to be in a continuous learning mode. There should be lot of communication among employees and technological tools that enhance performance. Brewer \& Speh (2001) proposed some SCM goals related to this perspective viz. product and process innovation, partnership management, information flows and their measures viz. product finalization point, product category commitment ration, number of shared data set, performance of competing technologies etc.

- Business process perspective: This perspective includes internal business processes. It ascertains whether the products and services are conforming to customer requirements. It covers both mission oriented processes and support processes. Brewer \& Speh (2001) proposed some SCM goals related to this perspective viz. waste reduction, time reduction, flexible response and unit cost reduction and their measures viz. supply chain cost of ownership, supply chain cycle efficiency, number of choices/average response time and \% of SC target cost achieved.

- Customer perspective: This perspective concentrates on customer focus and customer satisfaction. If customers were not satisfied, any business would fare poorly. Thus this perspective analyses customer and processes to ascertain adequate performance. Brewer \& Speh (2001) proposed some SCM goals related to this perspective viz. customer view of product and services, timeliness, flexibility and customer values and their measures viz. number of customer contact points, relative customer order response time, customer perspectives about flexible response and customer value ration etc.

- Financial perspective: This perspective deals with the financial databases and stresses on the need of automation on this count. According to Brewer \& Speh (2001), some SCM goals related to this perspective are profit margin, cash flow, revenue growth and return on assets with measures like profit margin by supply chain partner cash to cash cycle, customer growth \& profitability and return on supply chain assets.

\subsection{Framework of Beamon (1999)}

Beamon (1999) presented a supply chain measurement system that has three measures viz. Resources, Output and Flexibility. They explained that these measures have the goals of attaining high level of efficiency, high level of customer service and ability to respond to a changing environment.

The Figure 1 is an illustration of the performance measurement system in this framework. Each measure is accompanied by some performance measures. For example, resource measures cost so performance measures in this category are total costs of resources used, total costs of distribution including transportation and handling, total cost of manufacturing including labor / maintenance etc.

Output measures are concerned with the customer responsiveness. The performance measures here are total revenue, proportion of orders filled immediately, on-time deliveries, back order/ stock outs, amount of time between an order and delivery, total amount of time required to produce an item or batch, number of customer complaints etc. 
Flexibility measures deals with various flexibilities like the ability to change the output level of products, ability to changed planned delivery dates, ability to change the variety products produced and the ability to introduce and produce new products.

Beamon (1999) further commented, "Supply Chain models that utilize this framework can more completely characterize the supply chain system and the resulting reconfiguration effects, thus enabling the development of models that are more complete, accurate, and therefore, more effective".

\subsection{Framework of Gunasekaran (2004)}

Gunasekaran (2004) classified measures into strategic, tactical and operational levels of measurement (Figure 2). The aim was to enhance their visibility for the managerial decision-making. Let us see what these levels measure:

- Strategic Level: Top-level management decisions, investigation of broad based policies, corporate financial plans, competitiveness and adherence to organizational goals.

- Tactical Level: Resource allocation, measuring performance of goals set in strategic level, feedback on the mid-level management decisions.

- Operational Level: Data analysis, evaluation of decision of low level managers and workers, ensuring that goals set in tactical level are met.

As earlier said, these levels insure that the goals set in previous levels are met. For example, product development cycle time is present at strategic level as well as tactical under the supply chain activity plan. But in hierarchy its importance is much more at the tactical level. These levels are thus defined to assign measures to the places where they can be best dealt with. This framework maps the performance measures specific to organizational goal.

\subsection{Framework of Chan et al. (2003)}

This framework is based on fuzzy set theory. It uses fuzzy set theory to measure the integrated performance of complex supply chain. First the identification of appropriate performance measures is done and once identified each performance measure is given a weight by finding the normalized importance weight. A fuzzy performance grade is defined so that a performance score can be calculated. The results are converted into a performance index.

For identifying appropriate performance measures, for each process and sub processes of the supply chain, corresponding measures are grouped into processes and measures hierarchy.

In this framework (Fig 4.3), a performance measurement team (PMT) is suggested which has persons from various areas of the supply chain e.g. shop floor operators, process supervisors and plant managers etc. The members of PMT serve as evaluators and thus give weights to different performance measures. According to Chan et al. (2003) this framework gives a cross-organizational performance measurement method from a system perspective.

\subsection{Framework of Kleijnen \& Smits (2003)}

Kleijnen \& Smits (2003) gave an example of one division of a large multinational company's evaluation of logistical performance. The company followed the following five performance metrics.

- $\%$ of order delivered on time (Fill rate)

- $\%$ of order delivered as negotiated (Confirmed Fill rate)

- Difference between "on time" and "as negotiated" order delivery (Response delay)

- Total work in process (WIP) expressed as a $\%$ of the total sales. If this is less then there will be loss of business (Stock).

- Difference between actual delivery and delivery as negotiated (Delay).

They used economic theory for treating multiple performance metrics via the balanced scorecard approach. Simulation was used for performance measurement. They suggested that there are following challenges for performance evaluation in SCM:

- Selecting a specific supply chain.

- Determining performance metrics, sub-metrics \& applying BSC (Balance Score card) to determine the SC's main metrics.

- Designing a simulation model to explain how the SC's performance metric reacts to environment \& measurement control factors. 
- Performing sensitivity analysis to validate the simulation model.

According to them this results in both an integrated methodology for performance evaluation (cost/benefit analysis) of SC's and general results on the main drivers of these cost and benefits.

\subsection{Framework of Supply-Chain Operations Reference-Model (SCOR)}

SCOR is developed as a cross-industry standard for supply chain management. It uses a process reference model to explain a supply chain. The process reference model is a combination of business-process reengineering, benchmarking and best practices analysis. The process reference model is aimed at providing a framework for performance measures $\&$ best practices for standard processes. SCOR spans interactions pertaining to customers/ markets and transactions pertaining to products. SCOR is based on management processes like plan, source, make, deliver and return. It actually defines the supply chain as a integrated process of these management processes. It gets activated from the stage of supplier's supplier up to customer's customer. It is aligned with operational strategy, material, work and information flows. Thus SCOR enables communication among supply chain partners.

The heart of the SCOR system is a pyramid of four levels that represent the path a company takes on the road to supply chain improvement. The pyramid can be seen in the Figure 4. The top level defines the scope and content for the model and sets the basis for performance targets. Configuration level configures the supply chain so that the operational strategy can be implemented. The third level i.e. the process element level consists of process element definitions, information inputs and outputs, performance metrics, best practices and system capabilities to support best practices. The implementation level is concerned with defining practices to achieve competitive advantage.

SCOR thus provides list of performance measure for each activity and process in a supply chain, aligns these measures with the strategic objectives and provides the best practices for each measurement. It is therefore used to describe measure and evaluate supply chain.

\section{Summary}

Gunasekaran (2004) stated, "Supply chain management has been a major component of competitive strategy to enhance organizational productivity and profitability". This paper has attempted to discuss two topics, which are of prime importance in supply chain from the point of view of above statement i.e. benchmarking and performance measurement.

Benchmarking is a method of comparison of performance in order to create new standards for improving processes. Benchmarking helps in identifying the factors that are critical for success. The need for benchmarking arises when the company wishes to improve its operations or supply chain. Benchmarking is not a trivial process and needs a lot of efforts from organizations because the efforts here are directed towards comparing oneself with the "best in the trade".

There is plethora of research done in recent years for the nature and methodology of measuring performance in organizations. This is done in order to make a review of present, past and future. A few frameworks for performance measurement in a supply chain are discussed. This list is not complete but it gives an idea of the developments in the field of performance measurement.

\section{References}

Beamon, B. M. (1996). Performance measures in supply chain management. Proceeding of the 1996 Conference on Agile and Intelligent Manufacturing Systems. Rensselaer Polytechnic Institute, Troy, New York, NY, 2-3 October.

Beamon, B. M. (1999). Measuring Supply Chain Performance. International Journal of Operations and Production Management, Vol. 19, No. 3, pp. 275-292. http://dx.doi.org/10.1108/01443579910249714

Brewer, P. C. \& Speh, T. W. (2001). Adapting the balanced Scorecard to Supply Chain Management. Supply Chain Management Review.

Chan, F. T. S., Qi, H. J., Chan, H. K., Lau, H. C. W. \& Ip, R. W. L. (2003). A Conceptual model of performance measurement for supply chains. Management Decision: 2003, 41, 7: ABI/INFORM Global pp 635.

Donovan, M. (2005). Supply Chain Management: Plan to Succeed, [Online] Available: http://www.rmdonovan.com/pdf/perfor10.pdf site accessed 13/9/05.

Gunasekaran, A., Patel, C. \& McGaughey, R. E. (2004). A framework for supply chain performance measurement. Int. J. Production Economics, 87(2004), 333-347. http://dx.doi.org/10.1016/j.ijpe.2003.08.003

Kaplan, R. S. \& Norton, P. D. (1992). The Balance Scorecard measures that drives performance. Harvard Business Review, Jan-Feb, 1992, pp71-79. 
Kleijnen, J. P. C. \& Smits, M. T. (2003). Performance metrics in supply chain management. Journal of the Operational Research Society, 54, 507-514. http://dx.doi.org/10.1057/palgrave.jors.2601539

Mentzer, J. T. (2007). Achieving Competitive Advantage Through Supply Chain Management, [Online] Available:http://www.industryweek.com/articles/achieving_competitive_advantage_through_supply_chain_manag ement_13355.aspx

Morgan, C. (2004). Structure, speed and Salience: performance measurement in the supply chain. Business Process Management Journal, Vol. 10, No. 5, 2004 pp 522-536. http://dx.doi.org/10.1108/14637150410559207

Peters, K. (2005). Top Retail Companies Unite to Expand Supply Chain Best Practices, [Online] Available:http://www.internetretailer.com/2005/04/22/top-retail-companies-unite-to-expand-supply-chain-best-prac tices

Supply-Chain Operations Reference-Model (SCOR) Overview Version 7.0, Supply Chain Council, [Online] Available:www.supply-chain.org

Waters, D. (2003). Logistics: An Introduction to Supply chain Management. Palgrave Macmillan, Indian Reprinted ed. 2004.

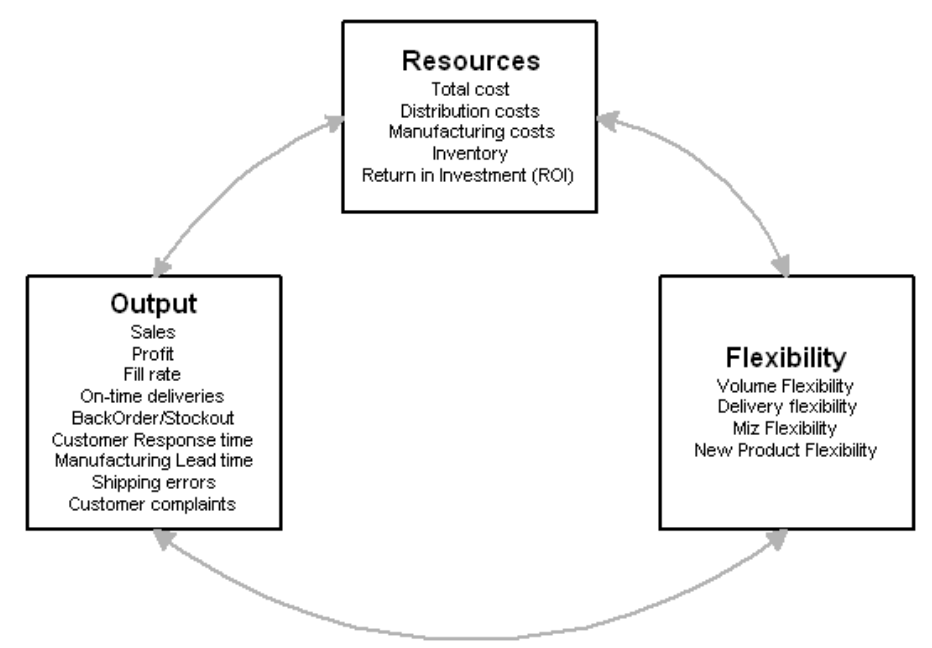

Figure 1. The Supply Chain Measurement System

(source: Based on Beamon, 1999) 


\begin{tabular}{|c|c|c|c|}
\hline \multicolumn{4}{|c|}{ Supply chain perform ance metrics fram ework } \\
\hline $\begin{array}{l}\text { Supply } \\
\text { chain } \\
\text { activity/ } \\
\text { process }\end{array}$ & Strategic & Tactical & Operational \\
\hline \multirow{8}{*}{ Plan } & $\begin{array}{l}\text { Level of customer pereived value of } \\
\text { product }\end{array}$ & Customer quet time & Onder enty methods \\
\hline & Variances agatnst budget & A Product developnent cycle time & Human resoume productivity \\
\hline & Order lead-time & Acounacy of foreasting technigues & \\
\hline & Information processing cost & Plaming process gole time & \\
\hline & Netproft Vsproductivity nato & Onder entry methods & \\
\hline & Total cycle time & Human resoune productivity & \\
\hline & Total casb flow time & & \\
\hline & Product development old time & & \\
\hline \multirow{6}{*}{ Source } & & Supplier deltrery performance & Effrciency of pumbase order gole time \\
\hline & & Supplier lead-time against industy nom & Supplerpring against market \\
\hline & & Supplerpning against market & \\
\hline & & Efriency of pumbase onder grle twe & \\
\hline & & Effciency of cash flow method & \\
\hline & & Supplier booking in provdures & \\
\hline \multirow{4}{*}{$\begin{array}{c}\text { Make/ } \\
\text { Assemble }\end{array}$} & Range of products and senvices & Penentage of defects & $\longrightarrow$ Penentage of Defects \\
\hline & & Costperopenation bour & $\longrightarrow$ Costperopenation bour \\
\hline & & Capacty atiligation & Human resoune productivity index \\
\hline & & Utitiquation of ewonomic onder quantity & \\
\hline \multirow{7}{*}{ Deliver } & $\begin{array}{l}\text { Flexibility of semice system to meet } \\
\text { oustomer needs }\end{array}$ & $\begin{array}{c}\text { Flexibility of semice system to meet } \\
\text { austomer needs }\end{array}$ & Qualty of delwered goods \\
\hline & $\begin{array}{l}\text { Effectiveness of enterprise distribution } \\
\text { planning schedule }\end{array}$ & $\begin{array}{c}\text { Effectivenes of enterprise distribution } \\
\text { plaming sobedule }\end{array}$ & On time delivery of goods \\
\hline & & Effectweness of delivery innotce methods & Effectiveness of deltwey insoice methods \\
\hline & & Penewtage of fmished goods in transit & Nomber of fanlthes delsery notes twotced \\
\hline & & Deltovy rhability pefomance & Percentage of urgent deliveries \\
\hline & & & Thomation richess in caming out delivery \\
\hline & & & (4) Delwey reliability performance \\
\hline
\end{tabular}

Figure 2. The Supply Chain Measurement System

(source: Gunasekaran, 2004) 


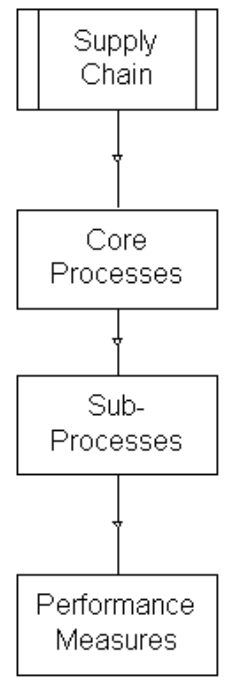

Figure 3. General structure of Processes and measures hierarchy (PMH) (source: Based on Chan, 2003)

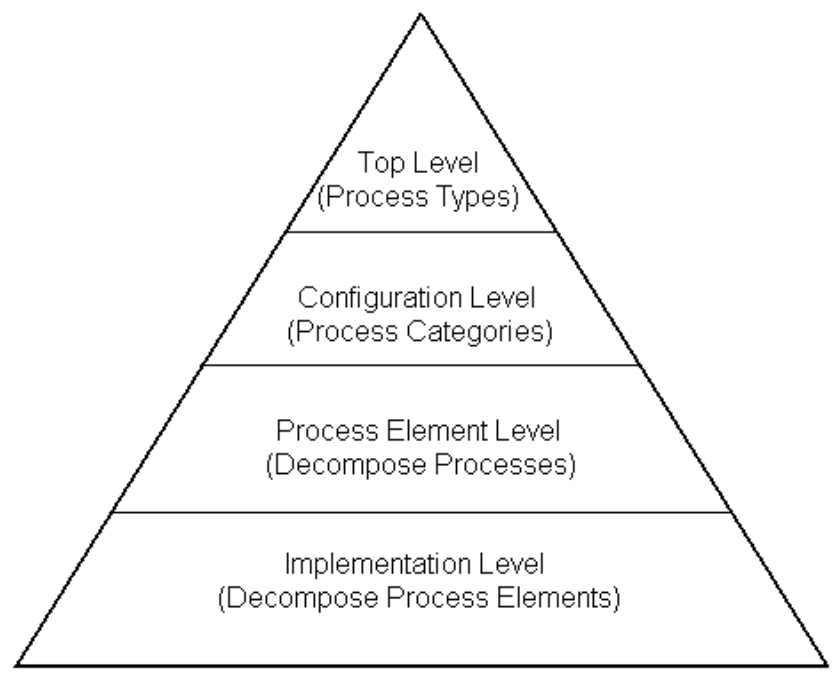

Figure 4. Supply Chain Operations Reference Model (source: Based on www.supply-chain.org) 